\title{
As atividades e a qualidade de vida de cuidadores de pacientes com doenças crônicas
}

\author{
Letícia Zanetti Marchi Altafim ${ }^{\mathrm{a}}$, Cristina Yoshie Toyoda ${ }^{\mathrm{b}, \mathrm{c}}$, \\ Danielle dos Santos Cutrim Garros ${ }^{\mathrm{b}}$ \\ ${ }^{a}$ Universidade Federal da Paraíba - UFPB, João Pessoa, PB, Brasil.

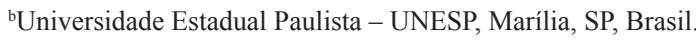 \\ 'Programa de Pós-graduação em Educação Especial - PPGEEs, \\ Universidade Federal de São Carlos - UFSCar, São Carlos, SP, Brasil.
}

\begin{abstract}
Resumo: Introdução: Com o aumento da população idosa em nosso país e, simultaneamente, com o crescente índice de morbidade de doenças crônico-degenerativas, temos observado cada vez mais pessoas buscando atendimento, tanto em nível ambulatorial quanto hospitalar. Essas pessoas são, muitas vezes, dependentes e quando retornam para casa precisam receber cuidados de algum membro da família: o cuidador. Realizar a prevenção e o tratamento dos problemas produzidos pelo impacto de fatores estressantes entre os cuidadores pode contribuir para reduzir ou protelar a institucionalização desses fatores. Com a melhora na qualidade de vida dos cuidadores, eles podem prestar melhor assistência aos pacientes. Objetivo: identificar a realidade de cuidadores de pacientes portadores de doenças crônicas e, a partir desse reconhecimento, implementar e avaliar a eficácia de uma proposta de intervenção junto a cuidadores que objetivou atenuar as condições estressantes advindas das práticas de cuidado. Método: Utilizou-se entrevistas com cuidadores familiares que foram gravadas e, posteriormente, transcritas para análise do conteúdo e elaboração da intervenção, no caso um curso, em que foram abordados aspectos informativos sobre a patologia e as atividades desempenhadas no cotidiano, assim como aspectos formativos como o autoconhecimento. Também foi aplicado um instrumento de qualidade de vida denominado Caregiver Burden Scale. Após a intervenção, o instrumento foi aplicado novamente para averiguar um possível confronto de dados e verificar a eficiência da intervenção. Resultados: Os resultados indicaram a importância da intervenção para melhora da qualidade de vida dos cuidadores.
\end{abstract}

Palavras-chave: Terapia Ocupacional, Procedimento Terapêtico, Pesquisa.

\section{The activities and quality of life of caregivers of patients with chronic diseases}

\begin{abstract}
Introduction: With the increase of the elderly population in our country and, simultaneously, the increasing morbidity rate of chronic-degenerative disease in general, the number of people seeking for attendance at day care centers and hospitals has also increased. Most of the time, these people are also dependent, when they return home, on the care provided by family members: the caregivers. To prevent and treat the problems caused by the stress factors among caregivers contribute to reduce or delay their hospitalization. In addition, improvement on the caregivers' quality of life could allow them to better help the patients. In this context, this research tried to understand the reality of the lives of caregivers of chronically ill patients, and with this knowledge, implement and evaluate the effectiveness of an intervention proposal. Objective: To attenuate the stress conditions of care activities. Method: The research used interviews with caregivers; these interviews were taped and later transcribed to analyze the content of answers and elaborate the intervention plan, which, in this case, was a course. The course consisted
\end{abstract}

Autor para correspondência: Cristina Yoshie Toyoda, Universidade Estadual Paulista, Campus de Marília, Av. Hygyno Muzzi, 737, CEP 17525-900, Marília, SP, Brasil, e-mail: cristoyoda@gmail.com

Recebido em Jan. 30, 2014; $1^{\text {a }}$ Revisão em Ago. 4, 2014; 2 ${ }^{\mathrm{a}}$ Revisão em Mar. 1, 2015; Aceito em Mar. 15, 2015. 
of informative aspects on the disease and daily life activities, as well as the formative aspect on self-knowledge. A quality of life instrument named Caregiver Burden Scale was also applied. After the intervention (course), the Scale was once more applied to verify the data and check for efficacy. Results: Results show the importance of the intervention on the caregivers' quality of life.

Keywords: Occupational Therapy, Therapeutic Proceeding, Research.

\section{Introdução}

Um estudo recente de cuidados com o cuidador (CARVALHO, 2003) mostrou que muitos dos indivíduos que trabalham diretamente com enfermos de doenças crônico-degenerativas têm apresentado patologias psíquicas, pois estão expostos a várias fontes de estresse que podem estar relacionadas:

1) À natureza da doença-como a imprevisibilidade do decurso da doença;

2) Ao tratamento-devido ao tipo de intervenção que será usada e uso da tecnologia para prolongar a vida;

3) À tomada de decisão- escolha de alternativas para o tratamento envolvendo muita responsabilidade;

4) À morbidade do paciente e a sua resposta psicológica- que depende da fase da doença e se as reações emocionais são negativas ou positivas;

5) À exposição a quadros de doenças que ameaçam a vida ou estão fora de possibilidade terapêutica de cura- como a morte iminente e em quadros severos de situação limite.

As fontes de estresse citadas acima, quando não elaboradas, provocam impactos na vida dos cuidadores nos seguintes aspectos:

Físicos - dores na coluna, cãimbras frequentes, perda da força muscular, dores constantes no corpo, fadiga crônica, perda de energia, desgastes de articulaçóes, falta de apetite;

Psico-emocionais - sintomas depressivos, alteração de memória, choro constante, distúrbios do sono, cefaléia, baixa concentração, agressividade;

Sociais - dificuldade em manter contato com as pessoas, se colocar em grupos, ficar isolado, uso abusivo de substâncias tais como medicamentos, tabaco, álcool;
Culturais - deixar de fazer atividades de lazer que interferem no aspecto cultural (CERQUEIRA; OLIVEIRA, 2002).

Para reduzir o estresse faz-se necessário um treinamento específico que deve privilegiar em primeiro lugar os aspectos informativos (informação teórica e treinamento prático) advindos, segundo Freitas e Santana (2002), do processo de ensino em saúde, em que cada profissional adota métodos de seleção, organizaçáo e explicaçáo dos conteúdos emergentes, de modo a direcionar as atividades de ensino, descrevendo objetivos, métodos, formas organizativas e meios adequados em favor do bem-estar do paciente, aliando-se ao familiar-cuidador; e, em segundo, os aspectos formativos - autoconhecimento, pois a partir da "[...] expressão dos sentimentos é que se descortina o jeito de ser de cada um, a percepçáo que demonstra sobre uma determinada situação e como se relaciona frente à realidade" (BIELEMANN, 2003, p. 136).

Para se trabalhar com os cuidadores é necessário promover o autoconhecimento e fazer com que seus sentimentos sejam expostos, para serem elaborados e recolocados em termos de aceitação do inevitável. Tal promoção permite, como diz Carvalho (2003), reparar a autoconfiança e autoestima de pessoas expostas às situaçôes limites no processo saúde e doença, relevantes às demandas físicas como transporte de paciente, apoio para prevenção de quedas, transferências do leito para a cadeira de rodas, mudança de decúbito no leito, troca de roupa de cama e do próprio paciente.

Somadas às demandas físicas existem também as demandas emocionais. Essas podem advir de três esferas: o cuidador, o paciente e a família. O primeiro enfrenta emocionalmente questôes que envolvem a morte, a instalação de incapacidade física, cognitiva ou mental, ou ainda, pelas demandas trazidas pelo próprio paciente; o paciente, por sua vez, demonstra insegurança quanto ao decurso da doença, frustração e apresentar exigências fora do contexto, tais como solicitaçôes de medicamentos além do necessário, requisitar troca constante da altura dos apoios para a cabeça (travesseiro, almofada), mudanças constantes de decúbitos; e, existem ainda outras demandas que são trazidas pelos familiares que acompanham os cuidadores, solicitando deles responsabilidades muito acima do que é exigido pelo seu papel. 
Numa fase em que o paciente não evolui ou não tem grandes mudanças no quadro, esse pode apresentar embotamento da sensibilidade ou negação, medo ou regressão, pensamento mágico e esperanças irreais, apelos, barganhas, desapontamentos, raiva e agressividade contra os cuidadores, por culpá-los pelo tratamento sem resultados aparentes (CARVALHO, 2003).

Os cuidadores, por sua vez, podem manifestar vários sentimentos, muitos deles positivos ligados ao afeto, como: apreço, gratidão, afeição, respeito, crença no funcionamento do tratamento; no entanto, tais sentimentos também podem ser negativos, como a incompetência para lidar com a situação, ressentimento em relação à dependência, comportamento exigente, possessividade, dificuldade de se acomodar à mudança da rotina domiciliar e desespero em relação à gravidade da enfermidade, prejudicando ainda mais a qualidade de vida do enfermo (GARRIDO; ALMEIDA, 1999).

Em países mais desenvolvidos existem redes de organizaçóes maiores e menores que são definidas como community care cujo grande objetivo é manter o paciente em sua casa oferecendo suporte para família e cuidador.

Já no Brasil o que predominam são estabelecimentos de redes articuladas por apoios formais e informais, que precisam ser estudadas, amparadas e aperfeiçoadas para terem uma função mais efetiva. Enquanto os países desenvolvidos se interessam e estudam os cuidadores como forma de se preparar para as grandes mudanças do século XXI, focando em temas atuais como o aumento da expectativa de vida, diminuição de membros das famílias, saída da mulher para o mercado de trabalho, maior número de separação entre casais, aumento da morbidade por doenças crônicas, países em desenvolvimento, como é o caso do Brasil, ainda principiam nesse tipo de estudo (MEDEIROS; FERRAZ; QUARESMA, 1998).

Constata-se que é fundamental para os profissionais da saúde recorrer à estratégia de ensino-aprendizagem para transmitir informaçôes ao familiar cuidador no processo de cuidar de pessoas em domicílio, principalmente quando essas são acometidas por doenças que desencadeiam processos crônicos e irreversíveis, uma vez que tal condição altera a trajetória de vida não somente da pessoa, mas também de seus familiares.

\section{Envelhecimento populacional e suas implicações}

Para situarmos melhor o contexto de cuidadores, devemos entender o processo de envelhecimento da população brasileira, visto que são os idosos aqueles que mais necessitam dos cuidados de outra pessoa, devido a alguma condição crônica de saúde.

A partir de 1940 iniciou-se o rápido processo de declínio da taxa de mortalidade que se prolongaria até a década de 1970 . Já na década de 1940, a taxa de mortalidade caiu $13 \%$, contra $16 \%$ nas quatro décadas anteriores (CAMARGO; SAAD, 1990).

A combinação de menores taxas de mortalidade e elevadas taxas de fecundidade determinou o aumento do crescimento vegetativo e, com isso, a população brasileira saltou de 41 para 93 milhôes de pessoas entre 1940 e 1970, com crescimento médio de $2,8 \%$ ao ano. No entanto, a estrutura etária da população não se alterou, pois a redução da mortalidade ocorreu, principalmente, devido à queda das taxas de mortalidade específicas da infância. Sendo assim, mais crianças foram "preservadas" e o efeito sobre a distribuição etária foi semelhante ao aumento da fecundidade, levando a um aumento da população jovem (CARVALHO, 1993). Nessas três décadas, as proporçóes de jovens e de idosos representaram, em média, respectivamente $42,3 \%$ e $2,5 \%$ do total.

O índice de envelhecimento da população (maiores de 64 anos $\times 100 /$ menores de 15 anos), que era igual a 6,4 em 1960, alcançou 13,9 em 1991, significando um incremento superior a $100 \%$ em apenas três décadas. Se no início do século a proporção de indivíduos que conseguia alcançar os 60 anos se aproximava de 25\%, em 1990 ela superava 78\% entre as mulheres e $65 \%$ entre os homens; a esperança de vida ao nascer entáo, já ultrapassava os 65 anos (INSTITUTO..., 1994).

As projeçốes das Naçôes Unidas (UNITED..., 1999, 2013) apontam para o Brasil uma população que, em 2000, atingiria 170 milhóes de habitantes, dos quais 49 milhôes com menos de 15 anos de idade e 8,7 milhóes acima de 65 anos. Para 2050, as Naçóes Unidas projetam que a população nacional ampliaria para 244 milhóes, sendo constituída por 49 milhôes de jovens e 42,2 milhóes de idosos. Por volta de 2080, a proporção de jovens e idosos deverá se estabilizar, com respectivamente $20 \%$ e $15 \%$ do total. Assim, a população brasileira vem sofrendo o que Silvestre et al. (1996) chamam de transição demográfica ao longo dos últimos anos, ou seja, a passagem de uma situação de alta mortalidade e alta fecundidade, com uma populaçáo jovem em franca expansão, para uma situação de baixa mortalidade e gradualmente, de baixa fecundidade, com uma crescente expectativa de vida, que começa a acarretar várias consequências sociais.

Essas consequências sociais são basicamente o aumento de gastos com internaçôes, sobrecarga dos 
serviços de saúde por parte dos idosos que apresentam problemas mais frequentes, aposentadorias, consumo alto de remédios, transporte especial e outros.

Veras explicita o processo de envelhecimento populacional, como segue:

A causa do rápido aumento da expectativa de vida no século passado foi uma substituição das causas de morte, anteriormente resultantes de doenças infecciosas e parasitárias, pelas doenças cardíacas, câncer e doenças neurológicas degenerativas. Essa alteração nos padróes de moléstias foi descrita por Omran como a transição epidemiológica. De acordo com essa teoria, à medida que as nações se modernizam, tendem a aprimorar suas condições sociais, econômicas e de saúde. As condiçôes de vida anteriormente favoráveis à disseminação de doenças infecciosas e parasitárias foram rapidamente substituídas por condiçóes de vida mais salubres e tecnologia médica aperfeiçoada. À medida que o risco de morte por doença infecciosa vai sendo reduzido, aqueles que escapam de morrer de tais doenças sobrevivem até a meiaidade e a velhice, quando enfrentam um risco maior de morrer de doenças degenerativas ou ainda permanecem incapacitados por longo período, necessitando de cuidados (VERAS, 1994, p. 28).

\section{Cuidadores}

Para uma compreensão do papel do cuidador, esse item tratará dos estudos desenvolvidos sobre o tema ao longo da história, bem como das diferentes concepçóes.

Os primeiros estudos relacionados aos cuidadores surgiram após o trabalho germinativo de Grad e Sainsbury, em 1963, chamando a atenção para as consequências da doença mental na vida de pessoas da família. Desde entáo, a literatura acerca dos cuidadores tem crescido, principalmente nos países desenvolvidos, marcadamente a partir da década de 1980, em decorrência de várias mudanças no cenário sociodemográfico e econômico, abordando primordialmente a área geriátrica com cuidadores de idosos com demência (MEDEIROS; FERRAZ; QUARESMA, 1998).

Outras doenças também têm sido estudadas nesse contexto, como: câncer, AIDS, asma, síndrome de Down, acidente vascular cerebral, epilepsia, doença de Parkinson, insuficiência renal crônica, artrite reumatóide, mal de Alzheimer, entre outras (ANDERSON; LINTO; STEWART-WYNNE, 1995;
BARNET; BOYCE, 1995; BECKHAM et al., 1995; CLIP; GEORGE, 1993; HOARE; RUSSELL, 1995; TOWNSEND et al., 1991; WICKS et al., 1997).

$\mathrm{Na}$ revisão da literatura sobre cuidadores domiciliares de idosos dependentes, que foi comentada por Barer e Johnson (1990), é consenso apenas a característica estressante da atividade de cuidar. Quando se fala de cuidadores não se tem uma definição clara desse termo, visto que diferentes autores usam o seu ponto de vista ou resultados de seus estudos para formular uma definição, muitas vezes, subjetiva. Porém, de uma forma genérica e sem muitas especificaçôes, diferentes autores definem o termo cuidador a partir de seus estudos com essa população, como sendo: "[...] quem assume a responsabilidade de cuidar, dar suporte ou assistir alguma necessidade da pessoa cuidada, visando à melhoria de sua saúde" (LEITÃO; ALMEIDA, 2000, p. 80), pessoa que chama a si a incumbência de realizar as tarefas as quais o doente lesado pelo episódio mórbido não tem mais possibilidade de desempenhar. Tais tarefas vão desde a higiene pessoal até a administração financeira da família. São cuidadores todos aqueles que procuram atender as necessidades dos pacientes, quer sejam necessidades físicas, quer sejam psicossociais (KARSCH, 2003).

Assim sendo, os cuidadores podem ser tanto a equipe de saúde como os familiares do paciente. De acordo com Carvalho (2003), pessoa que por delegação familiar ou por necessidade de emprego tomam para si, na primeira situação abdicando de outros interesses ou afazeres, já na segunda, são pessoas vendendo sua força de trabalho ao cuidar do outro, segundo Bretas (2003) e familiares ou pessoas cujas relaçóes são menos contratuais e mais de afeto ou com grau de parentesco ou de amizade e vizinhança com o cliente que está sendo cuidado, e essas pessoas têm importância e significado para aquele que está sendo cuidado (TRAVENSOLO, 2003).

Aprofundando um pouco mais sobre o uso desse termo, alguns autores dividem os cuidadores em formais e informais como sendo: contratados ou não. Duarte (1997) diz que cuidador formal é aquela pessoa contratada pelo paciente e/ou familiares, portanto é remunerado para exercer atividades de cuidado. Já Stone, Cafferata e Sangl (1987) complementam dizendo que cuidador formal pode ser um auxiliar de enfermagem, acompanhante ou empregada doméstica. Dessa forma, os cuidadores informais são familiares, amigos, vizinhos ou voluntários que assumem cuidar da pessoa doente quase sempre sem preparo e remuneração (DUARTE, 1997; STONE; CAFFERATA; SANGL, 1987). 
No presente estudo, o cuidador que foi o sujeito da pesquisa foi aquele que tem laços familiares com quem recebe os cuidados, sendo denominado cuidador familiar, ou seja, é aquela pessoa da família que mesmo não sabendo o papel que lhe cabe, está junto do paciente devido ao desejo de dar apoio, de solidariedade, de interesse em contribuir para que as suas necessidades sejam atendidas, também denominado cuidador informal, ou seja, sem formação na área da saúde, ou ainda cônjuge, filhos ou qualquer membro da família que voluntariamente ou não assumem a tarefa de cuidar do idoso (BIELEMANN, 2003; BRASIL, 1999; KARSCH, 1998).

Dada a importância e responsabilidade do cuidador na prestação dos cuidados necessários, podem também ser denominados cuidadores primários ou principal e secundário. Cuidador primário é definido como a principal pessoa responsável pela assistência ao paciente durante o curso da doença e a mais intimamente envolvida no cuidado dele (MEDEIROS; FERRAZ; QUARESMA, 1998; STONE; CAFFERATA; SANGL, 1987).

Já o cuidador secundário se restringe a outras pessoas que também fornecem assistência ao paciente, mas sem a principal responsabilidade (MEDEIROS; FERRAZ; QUARESMA, 1998). Colaborando nesse sentido, Stone, Cafferata e Sangl (1987) definem cuidadores secundários como sendo os familiares, voluntários e profissionais, que prestam atividades complementares.

Outros estudos levam em consideração o local da atividade dos cuidados para definir o cuidador. Cuidador institucional é aquele solicitado pela instituição em que o paciente se encontra internado, mas contratado pela família; já o cuidador domiciliar é aquele contratado também pela família por sugestão do médico que acompanha o paciente ou pela dificuldade de a família atender às necessidades dele (BRASIL, 1999).

As definiçôes não dão conta do processo de cuidar de um idoso dependente no domicílio, pois tendem a reduzir o foco da análise à atividade do cuidar em si, não dando importância a outras dimensóes envolvidas no processo, sendo que essas atividades são entendidas como uma obrigatoriedade para com o idoso dependente. Portanto, é algo inerente e natural às pessoas, sem uma contextualização social, histórica e cultural da vida desses cuidadores.

\section{Cuidado no domicílio}

Atender doentes em domicílio é uma prática que remonta à Antiguidade e está ligada à caridade e à solidariedade. Segundo Cunha (1991), essa atividade, citada no Velho Testamento, surgiu como recomendaçáo bíblica aos hebreus para o cuidado de doentes e puérperas em sua residência e, entre os judeus, encontram-se declaraçốes dos rabinos incumbindo-os de visitar os doentes para auxiliá-los a sair do sofrimento.

Nos Estados Unidos da América (EUA) o tratamento domiciliar é uma forte tendência e um terço dos hospitais oferece esse tipo de alternativa (SILVA, 1995). Segundo esse pesquisador, os EUA, nas últimas décadas, têm orientado os serviços hospitalares para dois grandes mercados de atenção à saúde: a cirurgia ambulatorial e a atenção domiciliar para os doentes crônicos e, progressivamente, os esquemas de tratamento de doenças mais prolongadas fora do hospital. A ênfase dada aos modelos de "tratamento domiciliar" é a abordagem integrada da equipe de saúde, modelo que não representa custos adicionais para o hospital em relação ao tipo tradicional de internação.

No Canadá, a experiência com internação domiciliar provém, principalmente, dos doentes portadores de câncer e doenças crônicas. Desde os anos 1960, o movimento de desospitalização tem sido intenso, acompanhado do desenvolvimento de novas tecnologias para cuidar das pessoas em casa (MC KEEVER, 2000).

$\mathrm{Na}$ América Latina existem experiências de internação domiciliar após a década de 1980, especialmente na Argentina, onde os programas sáo aprovados pelo órgão regulador de saúde daquele país e preocupam-se também com a atenção primária (ALBUQUERQUE, 1998; BORN, 2006).

É importante ainda destacar a experiência de Cuba que, desde 1984, vem desenvolvendo o modelo de medicina familiar. Há 29.646 médicos de família naquele país, os quais dão cobertura para $98,3 \%$ da população. Destaque-se que o modelo cubano tem influenciado muitas experiências em nosso país, especialmente no campo da assistência domiciliar, mas ainda estamos nos desenvolvendo com o Programa de Saúde da Família (PSF) e também com o Programa de Saúde do Idoso (ALBUQUERQUE, 1998).

O Hospital do Servidor Público Estadual de São Paulo foi pioneiro, segundo Kassab (2000), na implantação de programas de assistência domiciliar em 1968, criando normas, rotinas e seleção de profissionais para estruturação e desenvolvimento do programa. Portanto, foi modelo para o desenvolvimento de outros programas de assistência domiciliar, principalmente aquele ligado à Prefeitura Municipal de São Paulo, que existe oficialmente desde 1994. 
Em 1992, foi criado o Programa de Internação Domiciliar (PID) de Santos - litoral de Sáo Paulo e nos anos seguintes surgiram vários desses programas no país todo, como os de Hortolândia, Jundiaí e Campinas (1993), Volta Redonda (RJ, 1994), Paulínia (SP, 1995), Londrina (PR) e Quixadá (CE) em 1996, além de São Caetano do Sul, na grande São Paulo, que contempla hoje 400 famílias (AURICCHIO JUNIOR, 1999).

Apesar de os serviços municipais de assistência domiciliar objetivar em a melhoria da qualidade de vida da população atendida em saúde, verifica-se que não há muitos estudos sobre custo e benefício, o que aponta num sentido crítico que a esfera pública quer ter menor responsabilidade sobre os doentes e também quer reduzir gastos com a saúde ao aproveitar ao máximo os leitos hospitalares existentes para assim não precisar investir em construçôes e remodelaçóes de hospitais e centros de saúde.

Se a saúde é, como foi definida pela $8^{\mathrm{a}}$ Conferência Nacional, um fenômeno social, seria importante indagar "por que o cidadão que teve sua saúde abalada por fatores sociais não encontra uma rede de serviços de apoio para atendê-lo nos casos de doenças crônico-degenerativas?” Colocam-se como responsabilidade familiar as consequências de um fenômeno social. A família passa a arcar com todas as responsabilidades pela recuperação e/ou permanência das sequelas no indivíduo, sem contar com apoio de uma rede pública de serviços especializada para os casos crônico-degenerativos (MENDES, 1995).

Karsch (1998), nesse sentido, diz que para tornar o atendimento domiciliar um objeto de regulamentação na esfera pública é necessário trazê-lo para a esfera social. É preciso descaracterizá-lo como uma questão pessoal, individual, passando-se a considerar os determinantes sociais da doença para entendê-la como um fenômeno social.

No cuidado domiciliar é preciso sempre respeitar a casa das pessoas, suas peculiaridades, suas rotinas, condutas, culturas e crenças, além de considerar esses fatores quando se propóe alguma mudança na rotina doméstica ou na planta física da residência.

\subsection{Família}

Por ser considerada como o suporte básico do doente crônico, torna-se relevante destacar o papel da família no contexto dos cuidados e cuidador familiar.

A família, até pouco tempo atrás, era entendida como o conjunto de pessoas residentes sob o mesmo teto e que, entre si, apresentavam laços de parentesco e de afinidade. Essas características têm sofrido alteraçóes de todos os tipos e há sempre quem afirme que "a família está em crise" (SULLEROT, 1997).

A longevidade e a diminuição do número de nascimentos nas cidades brasileiras e no mundo estão "verticalizando" as estruturas familiares e uma nova forma de convívio está aparecendo: a "intimidade à distância”, segundo a qual as pessoas não moram na mesma casa, mas se visitam, telefonam e trocam favores (MELLO, 2002).

O cuidador domiciliar, ao ver uma pessoa de sua família com doença crônica e impossibilitada de cuidar de si, necessitando de alguém que a ajude, vê-se obrigado a responsabilizar-se por esse cuidado. Essa obrigação é determinada por seus próprios valores e princípios morais, mas também por laços afetivos. Essa escolha é consciente e ditada pela própria situação em que se encontra esse cuidador, ou seja, pelas circunstâncias que permeiam seu mundo familiar (MELLO, 2002).

As decisões para assumir os cuidados são mais ou menos conscientes e os estudos revelam que, embora a designação do cuidador informal seja decorrente de uma dinâmica, o processo parece obedecer a certas regras refletidas em quatro fatores:

- Parentesco: Com frequência maior para os cônjuges, antecedendo sempre a presença de algum filho;

- Gênero: Com predominância para a mulher;

- Proximidade física: Considerando quem vive na mesma residência da pessoa que requer os cuidados;

- Proximidade afetiva: Destacando a relação conjugal e a relação entre pais e filhos (KARSCH, 1998).

Néri (2002) aponta que as pesquisas nacionais e internacionais confirmam que a maior rede de suporte domiciliar ao doente crônico é formada por: cônjuges, filhos(as) e/ou parentes e amigos.

Como as mulheres são mais longevas do que os homens e, em geral, mais novas do que os maridos, a cuidadora familiar preferencial é a esposa. $\mathrm{Na}$ ausência da esposa e em segundo lugar, na hierarquia do compromisso, vêm os descendentes da segunda geração. Nesse caso, a candidata mais provável é afilha mais velha. Com frequência é de meia-idade, casada e tem filhos jovens. Em seguida, na hierarquia, vem a filha viúva, depois a solteira, também de meia-idade, com ou sem filhos. Raramente 
o cuidador é outro parente ou pessoa jovem e mais raramente ainda é um homem (PENNING, 1991, apud NERI, 2002, p. 25).

\section{Proposta de intervenção}

O objetivo da pesquisa foi promover através de atividades, no caso um curso, a melhoria da qualidade de vida de cuidadores familiares de doentes crônicos. Para isso, as atividades envolveram um treinamento específico, privilegiando aspectos informativos (informação teórica - sobre a patologia, legislação, informaçóes sobre assuntos emergentes e treinamento prático em atividades - posições e manobras que facilitem o cuidado e atividades da vida diária) e formativos (autoconhecimento - através de reflexôes sobre a própria vida, uso de role-playing, simulação de situaçóes e atividades expressivas).

No estudo de Mendes (1995) sobre cuidadores, constatou-se que as entrevistas foram uma fonte de informação para o cuidador e uma motivação para busca de novas informaçóes sobre a doença e o tratamento a ser administrado ao familiar dependente. As perguntas levavam-no a pensar sobre a doença, sobre os comportamentos que podem despertar no paciente, sobre a extensão da doença, tipo de tratamento que o paciente necessita, tempo de recuperação, a importância dos tratamentos em saúde na reabilitação do paciente e a avaliar o atendimento que tem recebido no hospital e nas consultas, assim como esclarecer dúvidas.

Quando o cuidador é a família pode-se ter intervençôes individuais ou em grupo. Elas podem visar três objetivos: apoio, resolução de problemas e desenvolvimento de habilidades de enfrentamento (CARVALHO, 2003).

Tanto nos Estados Unidos como na Europa há grandes investimentos das políticas públicas a fim de construir e manter redes de suporte a idosos diretamente ou prestando apoio a cuidadores: familiares, voluntários e profissionais. Isso é reconhecido, como mostrou a pesquisa de Lechner e Neal (1999), por programas públicos e privados, e essa pesquisa constatou que os cuidados oriundos de redes informais de apoio constituem a mais importante fonte de suporte a idosos.

Ao se reconhecer despreparado e, mesmo assim, ter que cuidar do outro, saber-fazer e saber-cuidar constitui uma reivindicação do ser cuidador e uma meta a ser alcançada. A necessidade de cuidar com zelo e solicitude são acompanhadas, na maioria das vezes, por sensaçóes de fragilidade, insegurança e abandono à própria sorte (SENA et al., 2000; HUNG et al., 2012). Nesse contexto, Mello (2002) coloca que ao procurar aprender para cuidar, esse cuidador também está cuidando dele próprio, pois sanando suas dificuldades, as sensaçóes de insegurança e abandono paulatinamente vão sendo dissipadas à medida que ele encontre quem o oriente, quem lhe tire as dúvidas, quem compartilhe com ele os momentos vividos no seu fazer diário.

\section{Método}

\subsection{Participantes da pesquisa}

Os participantes da pesquisa foram cuidadores de uma população com doença crônica e familiares próximos (esposa/marido, filho/filha, irmão/irmá, pai/mãe) que realizavam os cuidados na residência do doente e que náo tivessem participado em tempo algum de programas de apoio ou orientação a cuidadores.

Os sujeitos desta pesquisa foram constituídos, conforme a Tabela 1 , por seis cuidadores do sexo feminino, com idade média de 56 anos, sendo quatro esposas e outras duas, filha e irmá; todas com uma média de 5 anos de tempo de cuidado com o familiar doente. Esses familiares têm em média 60,3 anos, cinco com sequelas de AVE (Acidente vascular encefálico) e um com sequelas TCE (traumatismo crânio-encefálico).

\subsection{Local de coleta de dados}

O local da coleta foi um ambulatório de atendimento localizado numa universidade pública de uma cidade do interior de São Paulo no qual são atendidos doentes crônicos em nível de reabilitação.

Tabela 1. Caracterização dos cuidadores.

\begin{tabular}{ccccccc}
\hline Cuidador & Sexo & Idade & $\begin{array}{c}\text { Grau de } \\
\text { parentesco }\end{array}$ & $\begin{array}{c}\text { Tempo de } \\
\text { cuidado }\end{array}$ & $\begin{array}{c}\text { Doença do } \\
\text { familiar }\end{array}$ & $\begin{array}{c}\text { Idade do } \\
\text { familiar }\end{array}$ \\
\hline C1 & feminino & 74 & Esposa & 7 anos & AVE & 75 \\
C2 & feminino & 68 & Esposa & 2 anos & AVE & 72 \\
C3 & feminino & 52 & Esposa & 13 anos & AVE & 52 \\
C4 & feminino & 29 & Filha & 2 anos & AVE & 60 \\
C5 & feminino & 57 & Esposa & 3 anos & AVE & 61 \\
C6 & feminino & 56 & Irmã & 3 anos & TCE & 42 \\
\hline
\end{tabular}




\subsection{Material para coleta de dados}

Foi utilizada entrevista semiestruturada para a identificação do cuidador, aspectos necessários para o cuidado, impacto da rotina de cuidados para o cuidador, estágio da evolução da doença do familiar doente, suporte social e tópicos em relação à vida particular desse cuidador. O gravador foi usado para registrar o conteúdo das entrevistas.

Um instrumento denominado Caregiver Burden Scale (CBS) apropriado para medir o impacto das doenças crônicas na vida dos cuidadores foi administrado para uma análise mais aprofundada da qualidade de vida da população-alvo.

\subsection{Procedimento de análise de dados}

\subsubsection{Instrumento Caregiver Burden Scale aplicado pré e pós-intervenção}

A análise do instrumento foi feita de acordo com os procedimentos definido no próprio instrumento, ou seja, tendo as respostas dos cuidadores que poderiam ser: frequentemente, algumas vezes, raramente e de modo algum, com pontuação de 4, 3, 2 e 1, respectivamente; foi feita uma média aritmética para cada um dos quatro domínios e uma média para o instrumento todo (global ou total). Quanto mais próximo de 4, melhor a qualidade de vida e quanto mais próximo de 1 , pior a qualidade de vida do cuidador.

O resultado da aplicação do instrumento pré-intervenção juntamente com as respostas das entrevistas serviu para a elaboração do curso que visava atenuar as condições estressantes advindas das práticas de cuidado.

\subsubsection{Entrevistas}

Foram aplicadas e transcritas as entrevistas e, logo após, foi feita uma análise simples do conteúdo das entrevistas, ou seja, as partes da resposta que se mostravam relevantes e apresentavam alguma necessidade ou ênfase em comum por parte das cuidadoras eram separadas como foco para intervenção.

Após as atividades (curso) foi aplicado novamente o instrumento CBS para confronto de dados e para se verificar a eficácia da intervenção.

\subsubsection{Atividades (curso)}

$\mathrm{Na}$ intervenção, a análise se deu através da observação e do registro diário da pesquisadora sobre as atitudes e consideraçóes das cuidadoras sobre cada atividade e em cada encontro, para verificar se o objetivo de cada atividade ou dinâmica tinha sido atendido. O registro diário da intervenção consistiu em apontamentos sobre os depoimentos espontâneos e/ou solicitados das cuidadoras.

Foram também consideradas as observaçôes feitas pela pesquisadora quanto às expressões não verbais manifestadas durante as atividades propostas, tais como: sorrisos, balançar da cabeça indicando concordância, postura corporal de receptividade demonstrada por atitude de sentar-se na cadeira de modo confortável e relaxado, cumprimentos efusivos no início e término das atividades. Essas manifestaçôes foram consideradas como atitudes positivas para com a pesquisadora e sua proposição, não tendo sido observada durante toda intervenção sinais negativos ou contrários tais como: braços cruzados, sobrancelhas cerradas, meneio negativo da cabeça, boca contraída, ausência de sorriso e outros indicadores.

\section{Resultado}

\subsection{Entrevistas}

Constatou-se que as cuidadoras não sabiam definir o seu papel, tinham pouca ou nenhuma informaçáo sobre a doença do paciente, cuidavam por um longo período diário de seu familiar, demonstravam um misto de sentimentos positivos e negativos, tanto para com o familiar quanto para com a situaçáo em que se encontravam no momento e quando o familiar doente era dependente para locomoção elas passavam a ter dores pelo esforço físico. Constatou-se que as cuidadoras náo tinham tempo para cuidarem de si, tempo para lazer e nem planos para o futuro.

\subsection{Instrumento pré-intervenção}

O que se constatou foi que a cuidadora com pior qualidade de vida, ou seja, a que obteve maior pontuação total foi a C5, uma média de 2,68 de 4 pontos possíveis. Já as cuidadoras com melhor qualidade de vida, segundo o instrumento CBS foram as de número $\mathrm{C} 2$ e C4. O que se observou foi uma correlação com o déficit de suporte social, já que a cuidadora $\mathrm{C} 5$ náo recebe ajuda para realizar os cuidados e C2 e C4 recebem ajuda da família ou têm alguém contratado para auxiliar nos cuidados de seu familiar doente. 


\subsection{As atividades (curso-intervenção)}

O curso teve três encontros, totalizando 8 horas. Teve como programaçáo: aspectos teóricos sobre a patologia, atividades práticas (dinâmicas, simulação de situaçóes, incluindo, se necessário, role-playing), discussões em grupo sobre assuntos emergentes nas entrevistas, orientação para realização das atividades cotidianas nos cuidados com o familiar doente, além de atividades expressivas que propiciaram o autoconhecimento e a reflexão sobre suas atividades.

O trabalho profissional com os familiares cuidadores contemplou uma dupla vertente, composta por informação e reflexão. Foi necessário instruir os familiares nas especificidades da prática do cuidado, assim como atentar para os sentimentos que emergiam na lida diária com a pessoa doente.

Após cada atividade foi feito um diário de campo, no qual a pesquisadora anotava todas as impressóes de cada participante expressas através de opiniōes (o que achou dessa atividade?) e suas sugestóes, além da observação direta da própria pesquisadora e fatos mais importantes ocorridos durante as atividades.

Para melhor explanação sobre as atividades desenvolvidas, elas serâo apresentadas, bem como seus objetivos, o diário de campo com os resultados de cada atividade, segundo os participantes e observação direta da pesquisadora, que anotou os aspectos mais relevantes de cada atividade.

Apresentação: Considerando que as mulheres do grupo, de certa forma, já se conheciam, pois compareciam quase todos os dias no ambulatório e ficavam reunidas na recepção da unidade, enquanto seus parentes, que também faziam parte de um mesmo grupo, eram atendidos pelo(a) terapeuta ocupacional, podemos dizer que a apresentação não precisava ser muito elaborada, ou seja, ela deveria ser feita indicando: nome, o que gosta de fazer, o que náo gosta de fazer, fato marcante na vida (positivo ou negativo) e o que representa o cuidar de seu familiar doente.

Escultura com argila: Foram dadas às participantes: argila, espátulas e água para que elas fizessem uma escultura livre com o tema sentimentos. A atividade tinha como objetivo criatividade, expressão de sentimentos e autoconhecimento. Após o término da atividade, cada participante explicitou o que criou com a argila.

Além de proporcionar a criatividade das participantes, visto que todas conseguiram fazer algo com significado afetivo para elas, o manipular a argila, que era novidade para quase todas, contribuiu também para fazer aflorar sentimentos como: doação, carinho, cuidado, crença e prazer. Durante a atividade trocaram ideias e consideraçóes sobre o uso do material, fazendo comentários como: "nossa com argila dá pra fazer tanta coisa!".

Criando uma história: Uma participante iniciava uma história com tema livre, podendo escrever por um minuto e depois trocava sua história com a participante ao lado, que deveria completar o texto já escrito. Isso aconteceu até todas lerem e completarem a história de todas, com o objetivo de proporcionar criatividade, o compartilhar de ideias e opinióes, imaginação, percepção dos sentimentos que estavam ocorrendo e identificação das dificuldades e situaçóes comuns.

$\mathrm{Na}$ atividade de criar uma história, todas as participantes se divertiram muito, pois riram, deram palpites e manifestaram ansiedade por escrever logo. Ao lerem suas histórias em voz alta completada por todas as participantes, os comentários foram "como o pensamento de cada um é diferente, mas quando se escreve sobre um mesmo tema dá sentido" (C2).

Os cegos: Uma pessoa do grupo orientou outro participante com olhos fechados para encontrar uma bolinha dentro de um círculo de $3 \mathrm{~m}$ de diâmetro. Para chegar a esse círculo, o participante teve que percorrer um pequeno caminho com curvas amenas demarcadas por fitas no chão, sendo que aquele que orientava não permitia que a outra pessoa saísse da linha através das indicaçôes verbais, mencionando as direçóes a serem tomadas corretamente (para frente, para trás, para o lado esquerdo, para o lado direito) e o número de passos. O objetivo dessa atividade foi o desenvolvimento da confiança, habilidade, orientaçáo espacial e autocontrole.

Nessa atividade algumas cuidadoras ficaram um pouco com receio de cair ou tropeçar, mas no caminho que deveriam percorrer não tinha nenhum obstáculo e o mesmo náo era muito tortuoso, pois a única dificuldade era abaixar para pegar a bolinha. Todas se colocaram como tendo confiança na pessoa que iriam guiá-las e, sem utilizar uma venda nos olhos, todas conseguiram se controlar e demonstraram confiança, não abrindo os olhos em nenhum momento. Em relação à orientação espacial somente a cuidadora $\mathrm{C} 1$ saiu bastante do trajeto no início, porque tinha dificuldade em dar passos pequenos.

No final da atividade, todas reportaram um bem-estar por ter dado tudo certo e ainda comentaram que não é fácil ter confiança em alguém até você conhecer essa pessoa. E ainda, relataram que conseguiram entender um pouco melhor seus familiares doentes 
quando não querem "ninguém de fora" para cuidar, pois geralmente têm costumes e hábitos diferentes.

Role-playing: As participantes experimentaram algum tipo de privaçáo física ou sensorial pois a atividade objetivou a reflexão sobre o problema que é enfrentado pelo seu parente, além de fazê-las sentir as dificuldades reais que ele enfrentava e a resolução de problemas.

Para simular uma deficiência ou dificuldade foi proposto que duas participantes fossem mudas, duas com limitação de movimentos na mão direita, uma com visão unilateral e outra paraplégica, sem deambulação. A distribuição das deficiências ficou como relacionado a seguir:

\section{C1: não fala; \\ C2: não mexe a mão direita; \\ C3: não enxerga de um olho; \\ C4: não mexe a mão direita;}

\section{C5: não fala;}

C6: anda de cadeira de rodas.

O relato de uma das cuidadoras sintetiza as dificuldades vivenciadas e compreensão da real situação vivenciada pelo seu familiar com a disfunção neurológica:

É muito difícil...tem que ter paciência...dói um pouco... dá uma aflição...você quer mas não consegue... sei o que ele está passando, é duro.

Nessa atividade, as cuidadoras pediram para que as simulações de situações fossem feitas dentro da sala, pois tinham um pouco de vergonha de ir a um local externo; com o role-playing, puderam experimentar, de fato, algumas privaçóes de seus familiares, as dificuldades enfrentadas por eles e, de certa forma, o que sentem em relação a esse problema.

Palestra sobre AVE: Para melhor compreensão da dificuldade apresentada pelo seu familiar foi programada uma palestra enfocando aspectos sobre a doença, como: diagnóstico, causas prováveis, sequelas, tratamento, prognóstico. O objetivo foi esclarecer dúvidas, prestar informação detalhada sobre a patologia, em linguagem clara e objetiva.

No decorrer da palestra as cuidadoras fizeram perguntas sobre a doença e suas causas. Vale ressaltar que elas gostaram de saber que não é só a hipertensão arterial que é um fator de causa importante, mas outros como, diabetes, colesterol, tabagismo, falta de atividade física, dentre outros também são fatores causais. E através dessas informações comentavam com as outras sobre possíveis indícios no familiar antes de ele ter o episódio que culminou nas sequelas atuais. Pôde-se perceber pelos comentários das cuidadoras que o diagnóstico, muitas vezes, não foi dado de forma adequada e que os esclarecimentos sobre a doença eram superficiais, da mesma forma que o prognóstico dado pelo médico.

Debate sobre o cuidar: A atividade foi feita em grupo subdividido em dois subgrupos, um deveria defender a ideia do por que se deve cuidar do familiar (positivamente - sim) e o outro subgrupo de não cuidar ou porque, às vezes, alguém não cuida de um familiar (negativamente -não), seja por problemas de saúde, por questôes financeiras ou por uma relação pré-mórbida deteriorada com o familiar que necessita de cuidados. Quando foi proposto o debate, as cuidadoras gostaram da atividade, mas nenhum grupo queria se opor ao ato de cuidar, até que uma cuidadora deu um exemplo de uma dificuldade financeira. Então, outras se uniram a ela para defender esse ponto de vista. Contudo, todas deixaram bem claro que iriam defender esta ideia na atividade, mas que concordavam com o outro grupo, por princípio.

Nessa atividade, as cuidadoras poderiam expressar suas opiniōes sobre o cuidado e as dificuldades que encontram no cotidiano, além de pensarem conjuntamente na importância de seu papel como cuidador de doente crônico, muitas vezes, com a responsabilidade total pelos cuidados ao familiar doente e outras tarefas da casa.

Antes do debate foi explicitado pelas cuidadoras dos dois subgrupos um ponto em comum sobre a atividade de cuidar. A frase "Para cuidar deve-se ter acima de tudo carinho" sintetiza o sentimento das cuidadoras e o princípio para realizar a atividade de cuidar.

Após o debate, os aspectos positivos do ato de cuidar foram mencionados: o familiar doente necessita de apoio, a cuidadora é aposentada, cuidador náo precisa trabalhar, cuidador ama e deve cumprir o dever de esposa (casou na igreja e fez o juramento), mora junto com a pessoa doente, os filhos sabem que o cuidador é capaz, são desígnios de Deus -a fé e o amor encorajam e dão forças, a mulher deve cuidar do marido, tem de cuidar, pois não tem condiçóes de contratar uma pessoa para ajudar e é sozinha na casa, deve cuidar, pois tem responsabilidade sobre o outro, se tiver condiçóes financeiras pode contratar alguém para ajudar, mas deve estar por perto. 
O subgrupo encarregado de defender o não cuidar listou os fatores para tal atitude: $\mathrm{O}$ cuidador tem problemas de saúde, pode pagar uma pessoa para realizar os cuidados em tempo integral, tem ajuda financeira de outras pessoas, ele quer passear e não pode, se o doente não for o marido porque cuidar? - você não jurou nada, deve deixar os outros familiares cuidarem, deve arrumar uma pessoa qualificada, tem trabalho ou faz faculdade (alguma atividade que não pode "largar") e não tem tempo.

Atividade de cuidado interpessoal: A atividade foi realizada em dupla, em que uma cuidadora arrumou a outra, fazendo unha, penteando, efetuando arranjo no cabelo, entre outras coisas mais que a outra pessoa da dupla quis, como: maquiagem, massagem etc. O objetivo dessa atividade foi a melhora da autoestima, compartilhar gosto, intimidade com a outra pessoa do grupo, além de cuidados e desvelos pessoais.

\subsection{Instrumento pós-intervenção}

Após o curso e reaplicação do instrumento CBS houve mudanças em relação ao cuidador com pior qualidade de vida ou maior impacto ao cuidar, sendo que as cuidadoras C3 e C5 apresentaram o pior índice, o que pode ser explicado pelo fato de não terem nenhum apoio social no dia a dia dos cuidados com o marido e também por uma fonte externa de estresse, que foi comentada com a pesquisadora.

De acordo com a Tabela 2, quando comparados os resultados do instrumento CBS pré e pós-intervençáa, o que ocorreu foi a diminuição do índice para 4 cuidadoras (66,7\%), ou seja, melhora no índice de qualidade de vida (diminuiçẫo do impacto) e ligeiro aumento para 2 cuidadoras, o que pode ser explicado por fontes externas de estresse que não foram controladas nesta pesquisa.

Tabela 2. Comparação dos resultados do instrumento CBS pré e pós-intervenção.

\begin{tabular}{ccc}
\hline Cuidador & Pré & Pós \\
\hline $\mathrm{C} 1$ & 1,54 & 1,68 \\
$\mathrm{C} 2$ & 1,45 & 1,33 \\
$\mathrm{C} 3$ & 1,95 & 2,37 \\
$\mathrm{C} 4$ & 1,45 & 1,13 \\
$\mathrm{C} 5$ & 2,68 & 2,16 \\
$\mathrm{C} 6$ & 1,86 & 1,82 \\
\hline
\end{tabular}

\section{Considerações finais}

O curso foi um momento de informaçáo às cuidadoras e de autoconhecimento. A intervenção mostrou-se eficaz na medida em que trouxe para o grupo orientaçóes e reflexôes sobre a prática dos cuidados, assim como sobre aspectos da vida pessoal. Esses encontros de pessoas com problemas e dificuldades em comum fez com que as cuidadoras identificassem pessoas na mesma situação, ou seja, "compartilhar ideias faz encontrar soluçôes". Através disso, obtiveram aprendizagem e experiências novas, adquiriram mais conhecimentos e argumentos, perceberam algo no cotidiano que pode ser facilitado com novas atitudes ou açóes, identificaram sua limitação enquanto cuidadoras encarregadas do cuidado ao doente e enquanto seres humanos que precisam se cuidar e dar conta de atividades externas que antes náo eram sua funçáo e ainda continuar a cuidar da casa e, às vezes, até dos filhos.

No decorrer do curso, o sentimento presente na vida das cuidadoras foi o de amor e carinho. Saber das limitações e importância de se dividir a tarefa de cuidar com outros diminui a culpa (receio de náo cuidar tâo bem do familiar) e possibilitou a percepção de que poderiam postergar algumas atividades para depois, caso o tempo não fosse disponível.

O trabalho com a identificação do que cada uma gosta, fez com que as cuidadoras idealizassem mais planos para o futuro, com auxílio para investirem em projetos a longo prazo, pois muitas relataram não terem investido antes da intervenção devido à estagnaçáo da rotina ou ausência de perspectivas, devido ao estresse e demandas do ato de cuidar.

Antes da intervenção, observou-se uma atitude de troca de informaçôes básicas entre as cuidadoras, na sala de espera do ambulatório que seus familiares frequentavam. Após a intervenção, essa atitude mudou completamente, fato que pode ser constatado quando dois familiares cadeirantes foram desligados do tratamento fisioterápico. Naquele momento, uma terceira cuidadora passou a fornecer um suporte informal composto de apoio psicológico, encorajamento, busca de soluçóes conscientes para o problema.

\section{Referências}

ALBUQUERQUE, S. M. R. L. Associação Latino-Americana de Serviços de Saúde (ALASS). Revista Brasileira de Homecare, Rio de Janeiro, v. 6, p. 6-8, 1998.

ANDERSON, C. S.; LINTO, J.; STEWART-WYNNE, E. G. A population-based assessment of the impact and burden of caregiving for long-term stroke survivors. 
Stroke, Dallas, v. 26, n. 5, p. 843-849, 1995. http:// dx.doi.org/10.1161/01.STR.26.5.843. PMid:7740578

AURICCHIO JUNIOR, J. Um cenário promissor. Revista Brasileira de Homecare, Rio de Janeiro, v. 10, p. 53, 1999.

BARER, B. M.; JOHNSON, C. L. A critique of the caregiving literature. The Gerontologist, Washington, v. 30, n. 1, p. 26-29, 1990. http://dx.doi.org/10.1093/geront/30.1.26. PMid:2179063

BARNET, W. S.; BOYCE, G. C. Effects of children with Down syndrome on parents activies. American Journal of Mental Retardation, Washington, v. 100, n. 2, p. 115-127, 1995.

BECKHAM, J. C. et al. Patient predictors of caregiver burden, optimism, and pessimism in rheumatoid arthritis. Journal of Behavioral Medicine, Berlin, v. 20, n. 4, p. 171-178, 1995. http://dx.doi.org/10.1080/08964289.1 995.9933734. PMid:7620229

BIELEMANN, V. L. M. A família cuidando do ser humano com câncer e sentindo a experiência. Revista Brasileira de Enfermagem, Brasília, v. 56, n. 2, p. 133-137, 2003.

BORN, T. A formação de cuidadores: acompanhamento e avaliaçấo. In: SEMINÁRIO VELHICE FRAGILIZADA, 2006, São Paulo. São Paulo: SESC Avenida Paulista, 2006. Disponível em: <www.sescsp.org.br>. Acesso em: 27 mar. 2015.

BRASIL. Ministério da Previdência e Assistência Social. Secretaria de Estado de Assistência Social. Idosos: problemas e cuidados básicos. Brasília, 1999.

BRÊTAS, A. C. P. Cuidadores de idosos e o sistema único de saúde. Revista Brasileira de Enfermagem, Brasília, v. 56, n. 3, p. 298-301, 2003. http://dx.doi.org/10.1590/ S0034-71672003000300016. PMid:14694745

CAMARGO, A. B. M.; SAAD, P. M. A transição demográfica no Brasil e seu impacto na estrutura etária da população. In: FUNDAÇÂOO SEADE. $O$ idoso na Grande São Paulo. São Paulo, 1990. p. 9-25.

CARVALHO, J. A. M. Crescimento populacional e estrutura demográfica no Brasil. In: SEMINÁRIO "CRESCIMENTO POPULACIONAL E ESTRUTURA DEMOGRÁFICA”, 1993, Rio de Janeiro. Belo Horizonte: CEDEPLAR/UFMG, 1993.

CARVALHO, V. A. Cuidados com o cuidador. O Mundo da Saúde, São Paulo, v. 27, n. 1, p. 138-146, 2003.

CERQUeIRA, A. T. A. R.; OLIVEIRA, N. I. L. Programa de apoio a cuidadores: uma ação terapêutica e preventiva na atenção à saúde dos idosos. Psicologia USP, São Paulo, v. 13, n. 1, p. 133-150, 2002. http://dx.doi. org/10.1590/S0103-65642002000100007.

CLIPP, E. C.; GEORGE, L. K. Dementia and cancer: a comparison of spouse caregivers. The Gerontologist, Washington, v. 33, n. 4, p. 534-541, 1993. http://dx.doi. org/10.1093/geront/33.4.534. PMid:8375684
CUNHA, I. C. K. O. Organização de Serviços de Assistência Domiciliária de Enfermagem. 1991. 189 f. Dissertação (Mestrado em Enfermagem)-Escola de Enfermagem, Universidade de São Paulo, São Paulo, 1991.

DUARTE, Y. A. O. Cuidadores de idosos: uma questáo a ser analisada. O Mundo da Saúde, Sáo Paulo, v. 21, n. 4, p. 226-230, 1997.

FREITAS, M. C.; SANTANA, M. E. Implementação da estratégia de ensino-aprendizagem à família de paciente crônico. Revista Brasileira de Enfermagem, Brasília, v. 55, n. 2, p. 146-150, 2002. PMid:12514835.

GARRIDO, R.; ALMEIDA, O. P. Distúrbios de comportamento em pacientes com demência: impacto sobre a vida do cuidador. Arquivos de Neuro-Psiquiatria, São Paulo, v. 57, n. 2B, p. 427-434, 1999. http://dx.doi. org/10.1590/S0004-282X1999000300014.

HOARE, P.; RUSSELL, M. The quality of life of children with chronic epilepsy and their families: preliminary findings with a new assessment measure. Developmental Medicine and Child Neurology, New Jersey, v. 37, n. 8, p. 689-696, 1995. http:// dx.doi.org/10.1111/j.1469-8749.1995.tb15015.x. PMid:7672466

HUNG, J.W. et al. Factors associated with strain in informal caregivers of stroke patients. Chang Gung Medical Journal, Taiwan, v. 35, n. 5, p. 392-401, 2012. PMid:23127344.

INSTITUTO BRASILEIRO DE GEOGRAFIA E ESTATÍSTICA - IBGE. Características demográficas e sócio-econômicas da populaçáo. Anuário Estatístico do Brasil, v. 54, n. 1, p. 18-32, 1994.

KASSAB, G. E. F. A assistência domiciliária (AD) no Hospital do servidor Público Estadual de São Paulo, Hospital Dr. Francisco Moratto de Oliveira. In: DUARTE, Y.; DIOGO, M. Atendimento domiciliário: um enfoque gerontológico. São Paulo: Atheneu, 2000. p. 545-548.

KARSCH, U. (Org.). Envelhecimento com dependência: revelando cuidadores. São Paulo: EDUC, 1998.

KARSCH, U. M. Idosos dependentes: famílias e cuidadores. Cadernos de Saúde Publica, Rio de Janeiro, v. 19, n. 3, p. 861-866, 2003. http://dx.doi.org/10.1590/ S0102-311X2003000300019. PMid:12806489

LECHNER, V.; NEAL, M. The mix of public and private programs in the United States: implications for employed caregivers. In: (Org.). Work and Caring for the Elderly: international perspectives. Philadelphia: Taylor e Francis, 1999. p. 120-137.

LEITÃO, G. C. M.; ALMEIDA, D. T. O cuidador e sua qualidade de vida. Acta Paulista de Enfermagem, Sáo Paulo, v. 13, n. 1, p. 80-85, 2000.

MC KEEVER, P. Cuidado domiciliar no Canadá. In: CONGRESSO INTERNACIONAL DE ESPECIALIDADES PEDIÁTRICAS, 2000, Curitiba, Brasil. Curitiba, 2000. 
MEDEIROS, M. M. C.; FERRAZ, M. B.; QUARESMA, M. R. Cuidadores: as "vítimas ocultas" das doenças crônicas. Revista Brasileira de Reumatologia, Campinas, v. 38, n. 4, p. 189-192, 1998.

MELLO, R. A. P. Só quem cuida é que sabe: o vivido pelo cuidador domiciliar da pessoa com doença crônica. 2002. 92 f. Dissertação (Mestrado em Enfermagem)-Faculdade de Enfermagem, Universidade Federal de Minas Gerais, Belo Horizonte, 2002.

MENDES, P. B. M. T. Cuidadores: heróis anônimo do cotidiano. 1995. 167 f. Dissertação (Mestrado em Serviço Social)-Pontifícia Universidade Católica, São Paulo, 1995.

NERI, A. L. Cuidar de idosos no contexto da familia: questôes psicológicas e sociais. Campinas: Alínea, 2002.

SENA, R. R. et al. O ser cuidador na internação domiciliar em Betim/MG. Revista Brasileira de Enfermagem, Brasília, v. 53, n. 4, p. 544-554, 2000. http:// dx.doi.org/10.1590/S0034-71672000000400009. PMid:12138733

SILVA, T. L. Produtividade nos serviços de saúde: revisão conceitual e uma ilustração. 1995. 134 f. Tese (Doutorado em Administração de Empresas)-Fundação Getúlio Vargas, São Paulo, 1995.

SILVESTRE, J. A. et al. O envelhecimento populacional brasileiro e o setor saúde. Arquivos de Geriatria e Gerontologia, Rio de Janeiro, v. 1, n. 1, p. 81-89, 1996.
STONE, R.; CAFFERATA, G. L.; SANGL, J. Caregivers of the frail elderly: a national profile. The Gerontologist, Washington, v. 27, n. 5, p. 616-626, 1987. http:// dx.doi.org/10.1093/geront/27.5.616. PMid:2960595

SULLEROT, E. A familia: da crise à necessidade. Lisboa: Tipografia Peres, 1997.

TOWNSEND, M. et al. Evaluation of the burden of illness for pediatric asthmatic patients and their parents. Ann Allergy, Los Angeles, v. 67, n. 4, p. 403-408, 1991. PMid:1952296.

TRAVENSOLO, C. F. Qualidade de vida de um grupo de cuidadores familiares de portadores de doença de Alzheimer. 2003. 178 f. Dissertação (Mestrado em Gerontologia)-Pontifícia Universidade Católica, São Paulo, 2003.

UNITED NATIONS. Departament of Economic and Social Affairs, Population Division. Sex and Age distribution on the world population: the 2013 revision of ageing. New York: United Nations, 2013.

UNITED NATIONS. Department of Economic and Social Affairs, Population Division. Sex and Age distribution on the world population: the 1999 revision. New York: United Nations, 1999.

VERAS, R. P. País jovem com cabelos brancos. 2. ed. Rio de Janeiro: Relume Dumará, 1994.

WICKS, M. N. et al. Subjective burden and quality of life in family caregivers of patients with end stage renal disease. American Nephrology Nurses' Association Journal, Illinois, v. 24, n. 5, p. 527-528, 1997. PMid:9392735.

\section{Contribuição dos Autores}

Leticia Zanetti Marchi Altafim é autora do estudo e organizadora do texto. Cristina Yoshie Toyoda é orientadora do estudo, revisora de atualizaçáo bibliográfica e redatora final do texto. Danielle dos Santos Cutrim Garros é revisora final do texto. Todas as autoras aprovaram a versão final do texto. 